\title{
QUANTITATIVE VORONOVSKAYA TYPE RESULTS FOR A SEQUENCE OF STANCU TYPE OPERATORS
}

\section{P. N. Agrawal, Ana Maria Acu and Neha Bhardwaj}

Abstract. In this paper, we give some approximation properties of a sequence of operators defined by Stancu [21]. Its quantitative Voronovskaya type results are obtained with the aid of the second moduli of continuity. In order to study non-multiplicativity of these operators some Grüss-Voronovskaya type theorems are established.

Mathematics subject classification (2020): 41A10, 41A25, 41A30, 26A15. rem.

Keywords and phrases: Kantorovich operators, Voronovskaya type results, Grüss Voronovskaya theo-

\section{REFERENCES}

[1] A. M. ACU, H. GONSKA AND I. RAŞA, Grüss-type and Ostrowski-type inequalities in approximation theory, Ukranian Math. J., 63 (6) (2011), 843-864.

[2] A. M. ACU AND H. GonsKa, Classical Kantorovich operators revisited, Ukrainian Mathematical Journal, 71 (6) (2019), 843-852.

[3] P. N. Agrawal, N. ISPIR AND A. KaJla, Approximation properties of Bezier-summation integral type operators based on Pólya-Bernstein functions, Appl. Math. Comput., 259 (2015), 533-539.

[4] P. N. Agrawal, N. Ispir AND A. KaJla, Approximation properties of Lupaş-Kantorovich operators based on Pólya distribution, Rend. Circ. Mat. Palermo, 65 (2016), 185-208.

[5] R. BOJANIC AND F. CHENG, Rate of convergence of Bernstein polynomials for functions with derivatives of bounded variation, J. Math. Anal. Appl., 141 (1) (1989), 136-151.

[6] R. Bojanic And F. Cheng, Rate of convergence of Hermite-Fejer polynomials for functions with derivatives of bounded variation, Acta Math. Hungar., 59 (1-2) (1992), 91-102.

[7] P. L. Butzer, On the extensions of Bernstein polynomials to the infinite interval, Proc. Amer. Math. Soc., 5 (1954), 547-553.

[8] F. CHENG, On the rate of convergence of Bernstein polynomials of functions of bounded variation, J. Approx. Theory, 39 (3) (1983), 259-274.

[9] Z. DitZian And X. Zhou, Kantorovich-Bernstein polynomials, Constr. Approx., 6 (1990), 421-435.

[10] O. Duman, M. A. Özarslan and B. D. Vecchia, Modified Szász-Mirakjan-Kantorovich operators preserving linear functions, Turkish. J. Math., 33 (2009), 151-158.

[11] H. Gonska, Quantitative Aussagen zur Approximation durch positive lineare Operatoren, $\mathrm{Ph} . \mathrm{D}$. Dissertation, University of Duisburg, (1979).

[12] H. GonsKa, Degree of approximation by lacunary interpolators: $(0, \ldots, R-2, R)$ interpolation, Rocky. Mount. J., 19 (1) (1989), 157-171.

[13] H. GONSKA AND I. RAŞA, A Voronovskaya estimate with second order modulus of smoothness, in: D. Acu et al. (eds.): Mathematical Inequalities (Proc. 5th Int. Sympos., Sibiu 2008), Sibiu: Publishing House of "Lucian Blaga" University (2009), 76-90.

[14] V. Gupta, U. ABEL AND M. IVAN, Rate of convergence of Beta operators of second kind for functions with derivatives of bounded variation, Internal. J. Math. Sci., 23 (2005), 3827-3833.

[15] A. KAJla, A. M. ACU AND P. N. AgRAWAL, Baskakov-Szász-type operators based on inverse PólyaEggenberger distribution, Ann. Funct. Anal., 8 (1) (2017), 106-123.

[16] L. V. Kantorovich, Sur certains d veloppements suivant les polynSmials de la formede S. Bernstein I, II, C. R. Acad. Sci. USSR, 20 A (1930), 563-568, 595-600. 
[17] X. L. LiU, K. Y. XI AND S. S. Guo, Weighted approximation by Szász-Kantorovich operators, J. Central China Normal Univ. Natur. Sci., 36 (3) (2002), 269-272.

[18] L. LuPas AND A. LuPas, Polynomials of binomial type and approximation operators, Stud. Univ. Babes-Bolyai, Math., 32 (4) (1987), 61-69.

[19] D. MicLaus, The revision of some results for Bernstein Stancu type operators, Carpathian J. Math., 28 (2) (2012), 289-300.

[20] R. PÁltáneA, Representation of the $K$-functional $K\left(f, C[a, b], C^{1}[a, b]\right)-a$ new approach, Bull. Transilv. Univ. Bravo Ser. III, 3 (52) (2010), 93-99.

[21] D. D. STANCU, The remainder in the approximation by a generalized Bernstein operator: a representation by a convex combination of second-order divided differences, Calcolo, 35 (1998), 53-62.

[22] M. TAlPaU Dimitriu, Some results on global smoothness preservation by Stancu-Kantorovich operators, Journal of Science and arts, 3 (32), 2015, 219-224.

[23] V. Tотік, Uniform approximation by Szász-Mirakjan type operators, Acta Math. Hungar., 41 (1983), 291-307.

[24] V. Tотік, Approximation by Szász-Mirakjan-Kantorovich operators in $L_{p}(p>1)$, Anal. Math., 9 (1983), 147-167. 